\title{
Primary pure squamous cell carcinoma of the stomach: Unique case in one institution
}

\author{
Ana Marta Pereira, Joana Magalhães, Rui Ferreira Almeida, \\ Artur Trovão Lima, Albino Oliveira, Mário Nora
}

\begin{abstract}
Introduction: Pure primary gastric squamous cell carcinoma is rare, accounting for o.04$0.07 \%$ of all gastric cancers. The pathogenesis and behaviour are unclear and treatment strategy is controversial, and so, the prognosis is poor in almost all reported cases. The authors describe a rare case of long survival of the disease, and an unique case in an institution. Case Report: A Caucasian woman was referred to our hospital by a tertiary centre with a nonhealing, histologically inconclusive ulcer. Histologic examination of the biopsy taken during a repeated esophagogastroduodenoscopy revealed squamous cell carcinoma. The proposed treatment was total gastrectomy with D2 lymphadenectomy. Squamous cell tumor with no dysplasia or metaplasia was found in the specimen. Adjuvant chemotherapy was done with no relapse evident even 18 months
\end{abstract}

Ana Marta Pereira ${ }^{1}$, Joana Magalhães ${ }^{1}$, Rui Ferreira Almei$\mathrm{da}^{2}$, Artur Trovão Lima ${ }^{3}$, Albino Oliveira ${ }^{4}$, Mário Nora ${ }^{5}$

Affiliations: ${ }^{1}$ Resident in the General Surgery Department, Centro Hospitalar Entre Douro e Vouga, Santa Maria da Feira, Portugal; ${ }^{2}$ Hospital Assistant in the General Surgery Department and PhD student, Centro Hospitalar Entre Douro e Vouga, Santa Maria da Feira, Portugal; ${ }^{3}$ Graduated Hospital Assistant in the General Surgery Department, Centro Hospitalar Entre Douro e Vouga, Santa Maria da Feira, Portugal; ${ }^{4}$ Director of Pathology Department, Centro Hospitalar Entre Douro e Vouga, Santa Maria da Feira, Portugal; ${ }^{5}$ Director of General Surgery Department, Centro Hospitalar Entre Douro e Vouga, Santa Maria da Feira, Portugal.

Corresponding Author: Ana Marta Pereira, Centro Hospitalar Entre Douro e Vouga, General Surgery Department (8th floor), R. Dr. Cândido Pinho, 4520-211, Santa Maria da Feira, Portugal; Email: martappereira@hotmail.com

Received: 28 November 2017

Accepted: 29 December 2017

Published: 01 February 2018 follow-up. Conclusion: Gastric squamous cell carcinomas are rare tumors with unpredictable behaviour. The absence of glandular cells, dysplasia or metaplasia suggests a heterotopic foci origin, as well the squamous nature of the only lymph node metastasis. The success of this case is probably related to the early diagnosis, radical surgery and systemic adjuvant therapy.

Keywords: Stomach, Squamous cell carcinoma, Tumor

\section{How to cite this article}

Pereira AM, Magalhães J, Almeida RF, Lima AT, Oliveira A, Nora M. Primary pure squamous cell carcinoma of the stomach: Unique case in one institution. Int $\mathrm{J}$ Case Rep Images 2018;9:100885Zo1AP2018.

Article ID: 100885Z01AP2018

$$
* * * * * * * * *
$$

doi: 10.5348/100885Z01AP2018CR

\section{INTRODUCTION}

Primary squamous cell carcinoma (SCC) is an extremely rare malignancy even in high prevalence gastric carcinoma countries as Japan. According to literature, it accounts for $0.04-0.07 \%$ of all gastric carcinomas $[1,2]$.

Rörig described the first case in 1895 , and since then fewer than 100 cases have been reported [3]. Gastric SCC occurs in a male-female ratio of 5:1 and its prevalence is higher in the sixth decade of life, although it has been described as case in 17-year-old boy $[1,4,5]$.

The pathogenesis and natural history of this tumor are unclear. The optimal treatment strategy is controversial and the prognosis is poor $[1,2]$. 


\section{EDORIUM Journals}

We report unique case at our institution of a pure primary gastric SCC presented with dyspeptic complains who was treated with radical gastric resection combined with adjuvant chemotherapy. The patient is alive and disease free after 18 months of surgery.

\section{CASE REPORT}

A 63-year-old white female, with no relevant medical or surgical background, presented with epigastric pain and heartburn over a few months and with an esophagogastroduodenoscopy (EGD) report revealing an ulcer located in the proximal body of the stomach. Histological examination of the biopsy was taken during EGD that there was inconclusive, although Helicobacter pylori positivity. Given the suspicious aspect of the ulcer, two more EGDs were made with the same results.

The patient was submitted to Helicobacter pylori eradication (amoxicillin $1 \mathrm{~g}$, clarithromycin $500 \mathrm{mg}$, metronidazole 500 mgandesomeprazole $20 \mathrm{mg}$, twice daily during 14 days) and prolonging esomeprazole ten weeks more. Control EGD, twelve weeks later, demonstrated a non-healing ulcer (Figure 1) with histological analysis revealing squamous cell carcinoma involved by oxyntic mucosa, with no glandular component.

Otorhinolaryngology and Gynaecological evaluation excluded other extragastric squamous cell primaries.

Staging computed tomography (CT) scan (neck, thorax, abdomen and pelvis) excluded other potential origins for primary SCC and revealed no local invasion or secondary disease. Carcinoembryonic antigen and cancer antigen 19.9 were in normal range.

The patient underwent a total gastrectomy, D2 lymphadenectomy and reconstruction with a Roux-en-Y esophagojejunostomy.

Specimen analysis showed a deep ulcer, with 2.1x1.8 $\mathrm{cm}$ in size, with free margin resection, $4.2 \mathrm{~cm}$ from the gastroesophageal junction (Figure 2), and one out of 42 perigastric lymph nodes positive for metastatic disease (T3G1N1Mx). Microscopically, a well-differentiated squamous cell carcinoma with presence of keratinizing cell masses forming pearls, without glandular differentiation, was identified (Figure 3). No squamous metaplasia was present on adjacent gastric mucosa. Serosa surface was free of tumor. Immunohistochemistry was positive for Cytokeratine (CK) 5 (Figure 4) and p63, and negative for CK7 and CK2O.

One month after surgery, she started an adjuvant chemotherapy with cisplatin and 5-fluorouracil and completed six cycles with good tolerance. Eighteen months after surgery she was disease free.

\section{DISCUSSION}

Primary squamous cell carcinoma is very rare accounting for $<1 \%$ of all gastric malignancies. Caucasian's incidence is even more rare with only three case reports reported in literature, one of which was in Portugal [6]. It occurs mostly in men, in sixth decade of life, and the most common location is in the proximal stomach [1].

This type of tumor has gained interest because its unsolved pathogeny, unknown course and optimal treatment, taking consequently into a poor prognosis.

Since the first description by Rörig in 1895 different diagnostic criteria have been published [3]. Parks considered the possibility of gastric SCC in the absence of esophagus or cardia involvement and other SCC primary

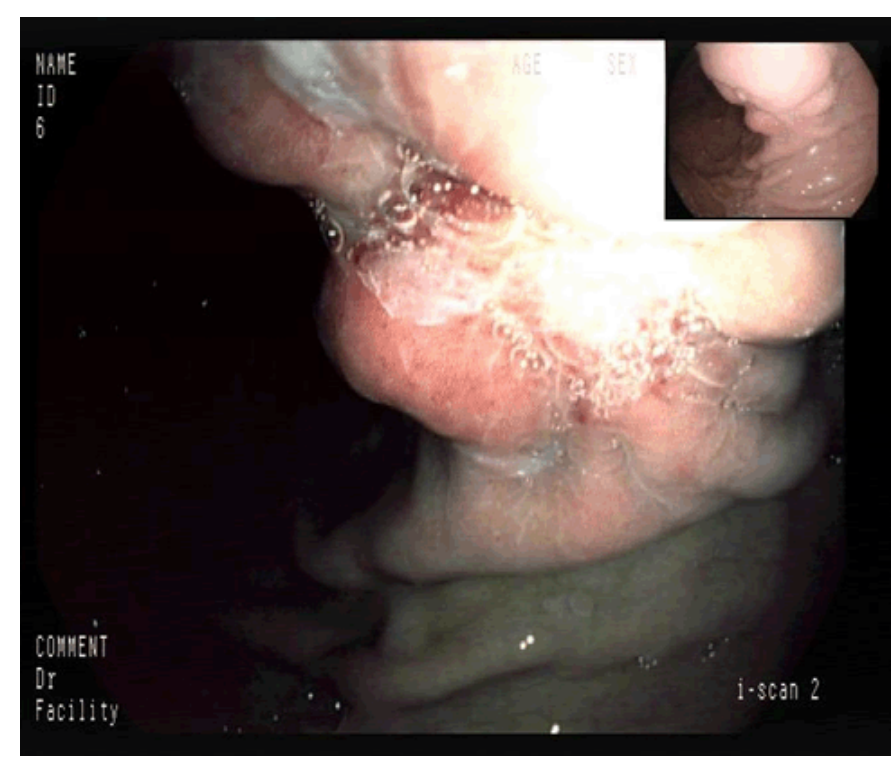

Figure 1: Esophagogastroduodenoscopy image showing $10 \mathrm{~mm}$ gastric ulcer located in the proximal body.

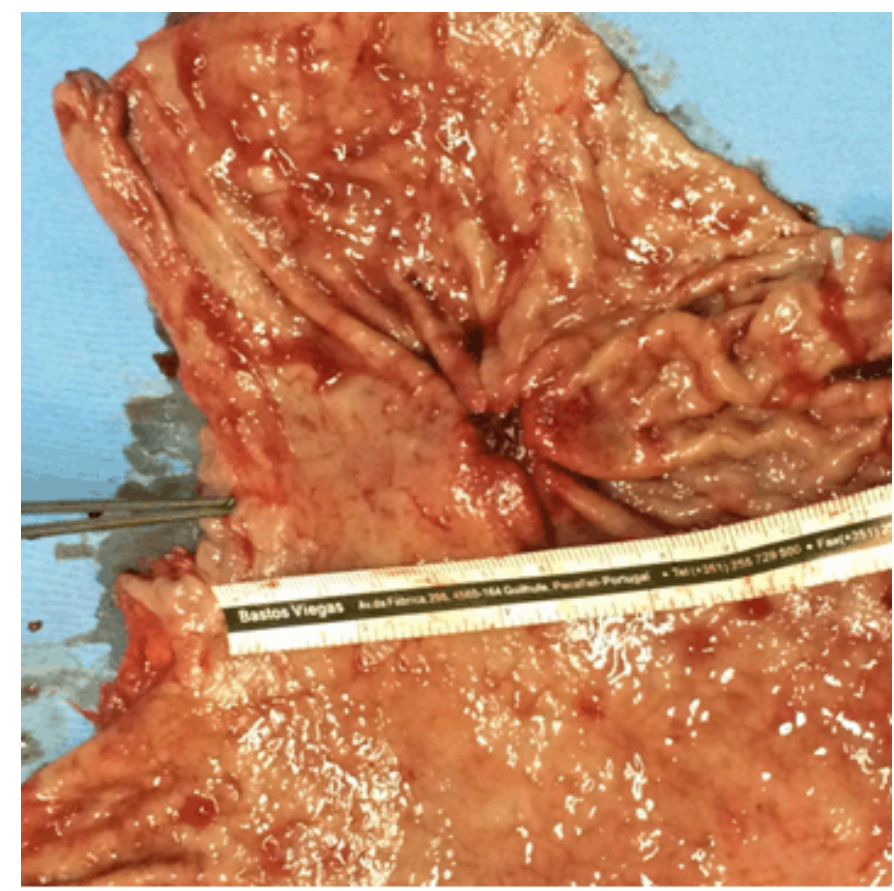

Figure 2: Specimen macroscopy: $2.1 \times 1.8 \mathrm{~cm}$ deep ulcer, placed on the posterior wall of the body region, $4.2 \mathrm{~cm}$ from the gastroesophageal junction. 


\section{EDORIUM Journals}
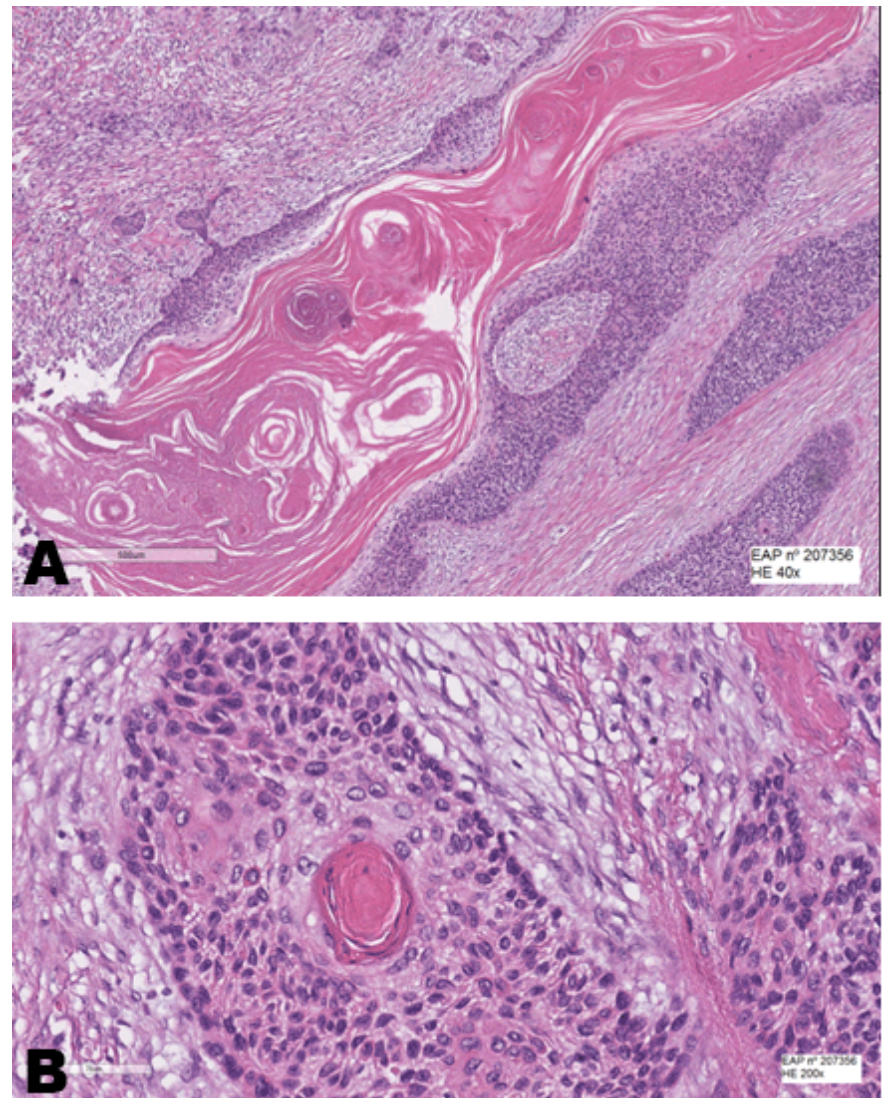

Figure 3: (A) Microscopy of the ulcer revealing well-differentiated squamous cell carcinoma with deep keratinization, with no glandular differentiation (H\&E stain, x40). (B) Keratin pearl formation (H\&E stain, x200).

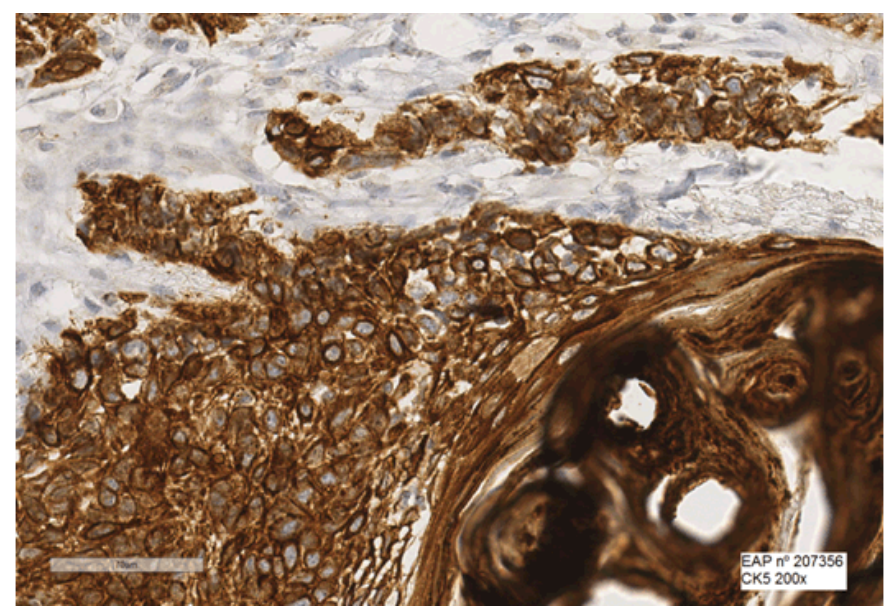

Figure 4: Immunohistochemistry study positive to $\mathrm{CK}_{5}$ (magnification: x200).

sources [7]. According to the diagnostic criteria for gastric SCC by the Japanese Gastric Cancer Association no glandular component can be present in the tumor and SCC must arise directly from gastric mucosa [8].

Our case represents a 100\% squamous cells tumor located in the proximal stomach, $4.2 \mathrm{~cm}$ distal to the gastroesophageal junction; other locations for SCC were excluded; therefore we could label it as primary gastric squamous cell carcinoma. Histologic criteria propose by Boswell and Helwig were also clear, namely the typical keratin pearl formations [9].

Gastric squamous cell carcinoma origin still remains poorly understood. Several theories have been hypothesized: squamous differentiation over a previous adenocarcinoma; benign squamous metaplastic lesions in the gastric mucosa; totipotent stem cells capable of squamous differentiation, or heterotopic squamous epithelium foci in the gastric mucosa $[1,4,6,10]$. In this case, neither metaplastic, dysplastic cells nor glandular component were reported.

Previous studies support the theory that squamous metaplasia might be the origin of these tumors [10]. Squamous metaplasia is related with chronic inflammatory conditions and seldom with other diseases such as peptic ulcers, syphilis, pernicious anemia, tuberculosis, corrosive gastritis, extreme cachexia and aberrant pancreatic tissue. In the stomach, it predominantly appears in the lesser curvature. So far the underlying metaplasia pathogenesis is unknown and whether it represents or not a premalignant lesion is yet to be clarified [11]. In this case, Helicobacter pylori infection might have contributed for chronic inflammation, despite no metaplastic focus was found in the specimen.

The origin of this tumor over an adenocarcinoma can be questioned. Carcinoembryonic antigen and cancer antigen 19.9 were negative in preoperative and follow-up study. Cytokeratins pattern can also give us a clue whether origin is in the glandular or squamous cells [12]. In this case, the immunohistochemical study is positive to squamous cell activity (positivity to $\mathrm{CK}_{5}$, p63, and $34 \beta \mathrm{E} 12)$ and negative to glandular pattern (CK7 and CK2O), suggesting tumor's origin might be from heterotopic squamous cell foci. This idea is supported by the fact that metastatic component in the lymph node is squamous.

The poor prognosis associated with gastric SCC might be related to advanced stage at time of diagnosis due to local aggressiveness and low responsiveness to chemoradiotherapy (unlike esophagus SCC) [12]. According to a Chinese surveillance, epidemiology and end results program (SEER) database with 163 primary gastric SCC, radiotherapy did not improved the prognosis, though it can be useful in the palliative setting [13]. There is a lack of information about adjuvant chemotherapy and its benefit is only described in individual cases, with different regimens.

The optimal treatment is radical surgery. In this case, the patient was submitted to adjuvant chemotherapy and is disease free 18 months after surgery. Long survival of these patients is rare so, nor the natural history of this pathologic entity, neither the usefulness of adjuvant chemoradiation are clear.

The squamous pure nature of this tumor, less frequently encountered in literature, is also of greater interest to the oncological research, taking into account 


\section{EDORIUM Journals}

www.ijcasereportsandimages.com

its behaviour is not confounded with a glandular component encountered in the adenosquamous cases. Another hypothesis is that different origins may explain this type of tumors, with distinct biological behavior and prognosis.

Despite the ideal treatment of gastric squamous cell carcinoma is not well established, the success appears to be related with early diagnosis and radical surgery, instead of systemic treatment. However, more data on gastric SCC cases is needed, in order to improve treatment and prognosis.

\section{CONCLUSION}

We report a case of an early phase pure primary gastric squamous (SCC) cell carcinoma in a Caucasian woman. Radical surgery and adjuvant chemotherapy were done with disease free status until now. Heterotopic squamous cell foci might have been the cause given that $100 \%$ of tumor and metastatic (lymph node) cells were squamous, with no metaplasia or dysplasia in the specimen. The rarity of this histological type of tumor and this particular case of long survival, make it an interesting model for oncological research.

\section{REFERENCES}

1. Wakabayashi H, Matsutani T, Fujita I, et al. A rare case of primary squamous cell carcinoma of the stomach and a review of the 56 cases reported in Japan. J Gastric Cancer 2014 Mar;14(1):58-62.

2. Quan J, Zhang R, Liang H, Li F, Liu H. The clinicopathologic and prognostic analysis of adenosquamous and squamous cell carcinoma of the stomach. Am Surg 2013 May;79(5):E206-8.

3. Rörig R. Primares Cancroid des Magens. Inaugural dissertation in thesis Wurzburg, P. Scheiner 1895.

4. Callacondo D, Ganoza-Salas A, Anicama-Lima W, Quispe-Mauricio A, Longacre TA. Primary squamous cell carcinoma of the stomach with paraneoplastic leukocytosis: A case report and review of literature. Hum Pathol 2009 Oct;40(10):1494-8.

5. Schwab G, Wetscher G, Dietze O, Schmid K, Pointner R. Primary squamous cell carcinoma of the stomach in a seventeen-year-old boy. Surg Today 1992;22(6):561-4.

6. Faria GR, Eloy C, Preto JR, et al. Primary gastric adenosquamous carcinoma in a Caucasian woman: A case report. J Med Case Rep 2010 Oct 29;4:351.

7. Parks RE. Squamous neoplasms of the stomach. Am J Roentgenol Radium Ther Nucl Med 1967 Oct;101(2):447-9.

8. Japanese Gastric Cancer Association. Japanese classification of gastric carcinoma, 3rd English ed. Gastric Cancer 2011;14:101-12.

9. Boswell JT, Helwig EB. Squamous cell carcinoma and adenoacanthoma of the stomach. A clinicopathologic study. Cancer 1965 Feb;18:181-92.
10. Saito S, Hosoya Y, Morishima K, et al. A clinicopathological and immunohistochemical study of gastric cancer with squamous cell carcinoma components: A clinically aggressive tumor. J Dig Dis 2012 Aug;13(8):407-13.

11. Cho YS, Kim JS, Kim HK, et al. A squamous metaplasia in a gastric ulcer scar of the antrum. World J Gastroenterol 2008 Feb 28;14(8):1296-8.

12. Barak V, Goike H, Panaretakis KW, Einarsson R. Clinical utility of cytokeratins as tumor markers. Clin Biochem 2004 Jul;37(7):529-40.

13. Dong C, Jiang M, Tan Y, et al. The clinicopathological features and prognostic factors of gastric squamous cell carcinoma. Medicine (Baltimore) 2016 Aug;95(34):e4720.

$$
* * * * * * * * *
$$

\section{Acknowledgements}

We would like to acknowledge the Anatomic Pathology Department of Centro Hospitalar Entre Douro e Vouga for the contribution in the diagnosis of this case and the availability to manage the figures; all the surgical esophagogastric team of General Surgery Department for the assistance in the management of this patient.

\section{Author Contributions}

Ana Marta Pereira - Substantial contributions to conception and design, Acquisition of data, Analysis and interpretation of data, Drafting the article, Revising it critically for important intellectual content, Final approval of the version to be published

Joana Magalhães - Substantial contributions to conception and design, Acquisition of data, Analysis and interpretation of data, Drafting the article, Revising it critically for important intellectual content, Final approval of the version to be published

Rui Ferreira Almeida - Substantial contributions to conception and design, Acquisition of data, Analysis and interpretation of data, Revising it critically for important intellectual content, Final approval of the version to be published

Artur Trovão Lima - Substantial contributions to conception and design, Acquisition of data, Revising it critically for important intellectual content, Final approval of the version to be published

Albino Oliveira - Substantial contributions to conception and design, Analysis and interpretation of data, Revising it critically for important intellectual content, Final approval of the version to be published

Mário Nora - Substantial contributions to conception and design, Revising it critically for important intellectual content, Final approval of the version to be published

\section{Guarantor of Submission}

The corresponding author is the guarantor of submission.

\section{Source of Support}

None 


\section{EDORiUM Journals}

\section{Consent Statement}

Written informed consent was obtained from the patient for publication of this case report.

\section{Conflict of Interest}

Authors declare no conflict of interest.

\section{Copyright}

(C) 2018 Ana Marta Pereira et al. This article is distributed under the terms of Creative Commons Attribution License which permits unrestricted use, distribution and reproduction in any medium provided the original author(s) and original publisher are properly credited. Please see the copyright policy on the journal website for more information.
Access full text article on other devices

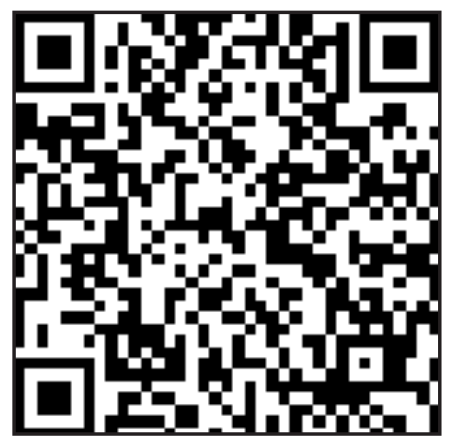

Access PDF of article on other devices

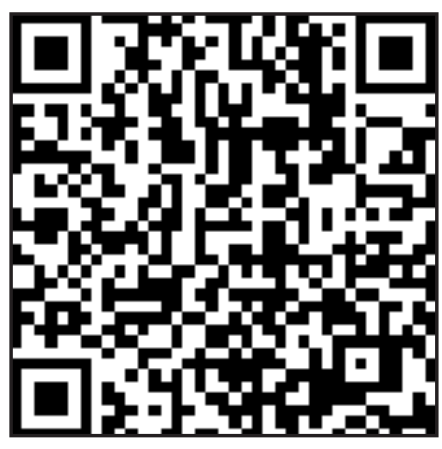

